Gut, 1986, 27, S1, 58-60

\title{
Role of dietitians in enteral feeding
}

\author{
C A RUSSELL
}

From the Department of Nutrition and Dietetics, Northampton General Hospital

SUMMARY Awareness of the nutritional requirements of inpatients has been sadly neglected for many years. Students in British medical schools are taught little about clinical nutrition and the role of the dietitian. Dietitians, on the other hand, spend four years learning the science of nutrition and dietetics. In most hospitals in Britain dietitians are responsible for giving advice on a wide range of therapeutic diets, and only a minority specialise in one particular aspect of nutrition and dietetics. Recent changes and developments in nutritional support have offered an exciting and interesting challenge to dietitians, who with their well established background in nutrition, can play an important part in the nutritional care team.

The earliest dietary record in a British hospital was that approved by the governing body of St Batholomew's Hospital in 1687. The first reference to therapeutic diets was made at the Radcliffe Infirmary, Oxford in 1837, and included "a diet which a suffering and exhausted nature sometimes requires after operations (mutton chops)."

When the first dietitians began to appear, initially in the United States of America the science of nutrition was new. Nursing sisters did not take kindly to "the idea of anything so new-fangled as a dietitian" as they jealously resented anybody interfering with the feeding of their patients. The first British dietitians to be known by that name were nursing sisters, and the first hospital dietetic department was established in 1924 at the Royal Infirmary, Edinburgh. Gradually the burden of the additional work on the nursing staff gave rise to the first graduate dietitian, and to maintain training standards the British Dietetic Association was formed in 1936. ${ }^{1}$

Today, most dietetic departments are understaffed, resulting in the hospital dietetic service failing to meet the expectations of the medical staff and also the expectations of the dietitians themselves; and although the potential role of the dietitian in nutritional support is definitely not fully exploited, she is often handicapped by existing commitments to other aspects of dietetics.

\section{Nutritional care teams}

The dietitian's role in providing nutrition for the

Correspondence to: Mrs C Russell, Dietetic Department, Northampton General Hospital, Billing Road, Northampton NN1 5BD, England. patient is clearly defined. Some evidence of malnutrition in medical and surgical wards has been reported in $30-50 \%$ of patients. ${ }^{23}$ Clearly the dietitian does not have the time to assess all hospital patients; and the responsibility of the patient's total care, in which nutrition is of prime importance, should be that of a nutrition care team

Recently there has been a noticeable impetus to establish formal nutrition teams. Though there are obvious benefits to be achieved by such a team, we must remember that a competent "team" can comprise a nurse, a dietitian, and the patient in close liaison with other professionals, without developing a structured nutrition team.

The nursing staff are in the best position for observing a patient's nutritional intake, and good communication between dietitians and nurses is vital.

\section{The role of the dietitian in enteral feeding}

Dietitians are often eager to establish a team but can come across obstacles such as lack of enthusiasm on the part of doctors. If a nutrition care team exists a senior dietitian should have an active role, preferably participating in both parenteral and enteral feeding. The role of the dietitian is manifold, and the Table summarises some of the tasks. At all times

\section{Table Role of dietitians in enteral feeding}

$\begin{array}{ll}1 & \text { Identification of patients requiring nutritional support } \\ 2 & \text { Patient monitoring } \\ 3 & \text { Reviewing products, systems, and medical literature } \\ 4 & \text { Education } \\ 5 & \text { Standardisation of feeding systems and hospital procedures } \\ 6 & \text { Research and development }\end{array}$


the dietitian must liaise closely with all members of the hospital staff working in the nutritional support of the patient.

IDENTIFICATION OF PATIENTS REQUIRING NUTRITIONAL SUPPORT

Early identification of eating problems is important. A hospital stay often results in a reduced nutritional intake, and the dietitian can allay patients' fears and improve their oral diet by discussing their problems, helping patients select their meals from the hospital menu, and suggesting suitable alternatives that may be available.

Sip feeding can effectively improve a patient's total energy and nitrogen intake, and the dietitian needs to use her skills to develop palatable recipes for nourishing sip feeds. Gentle persuasion may also be called on to encourage patients to take such drinks.

There is still often a reluctance to start tube feeding, and the dietitian must be prepared to take the initiative, if indicated. In many hospitals it may be the dietitian who assesses the nutritional state of the patient, estimates the nutritional requirements, and is responsible for prescribing and reviewing the feeding regimen.

\section{PATIENT MONITORING}

Together with other members of the team, the dietitian takes part in routine patient monitoring throughout the patient's stay in hospital. A daily record of the patient's consumed oral diet and the volume of enteral feed administered will enable the dietitian to calculate the total nutritional intake. The data may be required for detailed balance studies, for dovetailing feeding regimens, or simply to see if the patient's nutritional requirements are being achieved.

REVIEWING PRODUCTS, SYSTEMS, AND MEDICAL LITERATURE

A survey in 1981 showed that $51 \%$ of tube feeds given to hospital patients were "home made" in hospital kitchens at the direction and under the supervision of the dietitian. ${ }^{4}$ Attitudes and concern about microbiological contamination ${ }^{5-7}$ have resulted in more hospitals changing to commercially prepared enteral feeds.

It is up to the dietitian to keep abreast of the ever increasing range of enteral feeds and to help choose feeds and administration systems used. Current medical literature regularly reports on research into clinical nutrition. By keeping up to date with the literature and attending conferences and postgraduate courses, dietitians can make useful contributions to team discussions and decisions.
Several specialist interest groups of the British Dietetic Association exist, and dietitians experienced in enteral and parenteral nutrition have established the Parenteral and Enteral Nutrition Group (PENG). Meetings include presentations by invited guests and a number of excellent original contributions from the members of the group. The meetings provide an active forum for information sharing. Two guidance documents have also been produced by the group,${ }^{8}$ one outlining the dietitian's role in nutritional support and one giving guidelines for the microbiological control of enteral feeding.

\section{EDUCATION}

The educational role of the dietitian includes the patients and their relatives, the nursing, catering, and medical staff. She will be called on to explain to both patients and their relatives, the need for nutritional support, and, together with the nursing staff, may help to train patients and relatives to manage the feeding themselves either in the hospital or at home.

Regular lectures by dietitians are routinely given to student nurses in many hospitals. The subject of nutritional support is usually taught, but where possible this teaching should be continued at ward level and through tutorials and study days.

The catering staff have an important part in the nutrition of the patient and should learn the skills of diet cookery and preparation of feeds and sip feeds as appropriate. The dietitian should provide them with regular instruction and advice.

The training in clinical nutrition in our medical schools is limited, and the dietitian should help to redress the balance by working closely with the medical staff. If there is a nutrition team in the hospital it is well worth while introducing junior medical staff to the members of the team and explaining the role of each member and the policies of the team. Formal or informal lectures, together with a copy of any guidance notes produced by the team, help to improve the junior doctor's knowledge of clinical nutrition.

Last but not least, the dietitian must be mindful of her own needs for postgraduate education and try to attend appropriate lectures and conferences. By working with doctors, nurses, biochemists, and pharmacists, she can improve her knowledge of their specialities.

STANDARDISATION OF FEEDING SYSTEMS

A standard simplified approach to enteral feeding results in a more efficient and accurate administration of feeds by the nursing staff. The dietitian should work with the nursing procedures committee to fomulate procedures for enteral feeding. 
RESEARCH AND DEVELOPMENT

Forming a nutrition team often stimulates research projects at varying levels. It offers all members of the team the opportunity to gain experience in research methods. The work of the dietetic service should be monitored and evaluated and an annual report produced stating the time spent in enteral and parenteral (if applicable) nutrition, in addition to an annual report from the nutrition team.

\section{COMMUNITY WORK}

Nutritional support requires continuing care. Tube feeding can be successfully managed at home with dietetic, nursing, and medical support and supervision. Patients who have received nutritional support in hospital require regular dietetic follow up to ensure that an adequate diet is being taken.

\section{Conclusions}

The dietitian evolved from the nursing profession and established herself as an authority on nutrition and dietetics. She has a genuine interest in the nutrition of hospital patients but sometimes requires encouragement from the medical staff to develop her role in enteral nutrition. Once established she can make important contributions to the hospital nutrition care team.

The dietetic profession is predominantly female, and with no disrespect to my male dietetic colleagues the female gender has been used throughout the text, though the writing applies to both sexes.

\section{References}

1 Hutchinson E. The British Dietetic Association 1936-1961. London: Newman Books, 1961.

2 Bistrian BR, Blackburn GL, Vitale J, et al. Prevalence of malnutrition in general medical patients. JAMA 1976; 235: 1567-70.

3 Hill GL, Blackett RL, Pickford L, Burkinshaw L, et al. Malnutrition in surgical patients. Lancet 1977; i: 689-92.

4 Tredger J, Bazin C, Dickerson JWT. Naso-gastric tube feeding - a survey to investigate current practices and attitudes of dietitians. Journal of Human Nutrition, 1981; 35: 118-22.

5 Casewell MW. Nasogastric feeds as a source of Klebsiella infection for intensive care patients. Research and Clinical Forums 1979; 1: 101-5.

6 Bastow MD, Allison SP, Greaves P. Microbial contamination of naso-gastric feeds. Hum Nutr Appl Nutr 1982; 36A: 213-17.

7 Anderton A. Microbiological aspects of the preparation and administration of naso-gastric and naso-enteric tube feeds in hospitals - A review. Hum Nutr Appl Nutr 1983; 37A: 426-40.

8 The Parenteral and Enteral Nutrition Group of the British Dietetic Association. Dietitians' involvement in nutritional support. Birmingham: British Dietetic Association, 1984.

9 Anderton A, Howard JP, Scott D. Microbiological control in enteral feeding. Birmingham: British Dietetic Association, 1986. 